\title{
MORPHOMETRIC ANALYSIS AND SEXUAL DIMORPHISM OF HYOID BONE IN TELANGANA POPULATION
}

\section{Syeda Sadia Sameera ${ }^{1}, \mathrm{~K}$ Ephraim Vikram Rao ${ }^{* 2}$.}

${ }^{1}$ Assistant Professor, Department of Anatomy, Deccan College of Medical Sciences, Hyderabad, Telangana, India.

${ }^{* 2}$ Assistant Professor, Department of Anatomy, Gandhi Medical College, Secunderabad, Telangana, India.

\section{ABSTRACT}

Introduction: Determination of sex is of crucial importance in forensic investigations, when only a part of the body or skeletal remains are available. The present study focussed on the sexual dimorphism of hyoid bone in Telangana population by using morphometric analysis.

Materials and methods: The present study was carried out on a total of 60 hyoid bones in which 30 were of male and 30 were of female individuals. The bones were obtained from the department of Anatomy, Osmania Medical College and Deccan College of Medical Sciences, Hyderabad. Damaged and deformed bones were excluded, and only fully intact bones were included in the study. Lengths of greater horns, lengths of lesser horns, total hyoid length, and distance between distal ends of right and left greater horns, width of the body, length of the body and the thickness of the body of hyoid bone were measured by using sliding calipers.

Results: All parameters showed significant difference between the male and female groups. The measurements of all the parameters were significantly higher in males than in females.

Conclusion: All parameters used in the present study confirmed sexual dimorphism in hyoid bone. Hence, hyoid bone can be considered in forensic investigations or anthropological studies to determine the sex of an individual.

KEY WORDS: Sexual dimorphism, Hyoid bone, greater horn, Lesser horn, Sex determination.

Corresponding Author: Dr. K Ephraim Vikram Rao, Assistant Professor, Department of Anatomy, Gandhi Medical College, Musheerabad, Secunderabad, Telangana, India.

Mobile Number: 09949353025 E-Mail: dr.ephraimvikram1@gmail.com

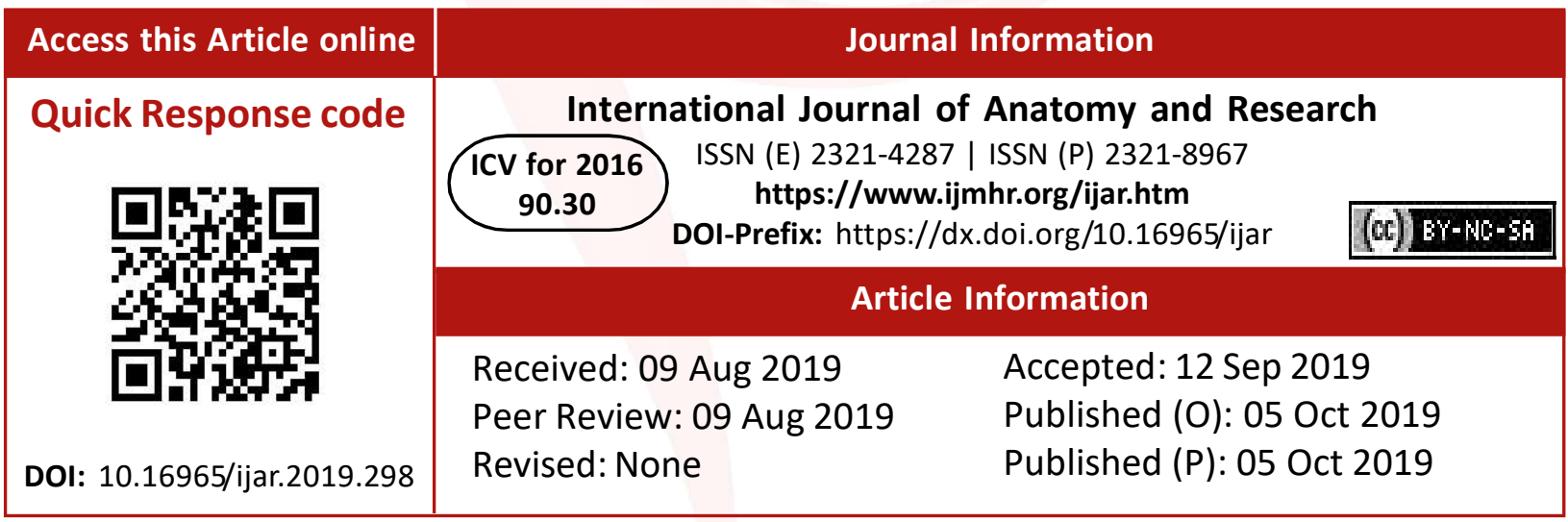

INTRODUCTION

Hyoid bone is a part of the viscerocranium which is placed between the root of the tongue and the thyroid cartilage. It is connected to the thyrohyoid membrane and is located at the level of fourth cervical vertebra. It consists of a body, a pair of greater and a pair of lesser horns [1]. Hyoid is unique, as it is the only bone in the body that has no bony articulations. It is suspended by muscles and ligaments and is responsible for the maintenance of airway, deglutition and preventing regurgitation [2]. Identification of an individual is an important task in forensic investigations; sex determination is one of the primary characteristics of identification of the individual along with estimation of age and stature. Among all, sex determination is a first and a very crucial step in human identification [3].

Identification of an individual is a very difficult task when the dead body is decomposed, 
mutilated, badly burnt or a small part of a body or fragments of a bone are found. Several studies have been carried out to determine the sex of an individual. Different bones have different degrees of accuracy in sexing the adult from the skeletal remains. The degree of accuracy is $100 \%$ in complete skeleton, $95 \%$ for the pelvis, $90 \%$ for the skull, $98 \%$ for the pelvis and skull together, $80 \%$ for long bones [4]. The hyoid bone has drawn less attention in sex determination. The present study aims to determine the sex of an individual based on the morphometric measurements of the hyoid bone in Telangana population.

\section{MATERIALS AND METHODS}

The present study consisted of a total of 60 adult hyoid bones in which 30 were belonging to males and 30 were belonging to females. These bones were collected from the department of Anatomy, Osmania Medical College, Hyderabad and Deccan College of Medical Sciences, Hyderabad. Fully intact bones were included, deformed and damaged bones were excluded from the study. The length of greater horn on right and left sides (Figure 1), distance between distal ends of the right and left greater horns (Figure 2), width (side to side dimension) of the body (Figure 3), total length (From the anterior surface of the body at its middle to the tubercle of greater horn of the hyoid bone, height (From the upper border to lower border of body of hyoid) of the body (Figure 4) and the thickness (Antero-posterior) of the body (Figure 5) were measured using sliding calipers.

Fig. 1: Showing the length of the greater horn.

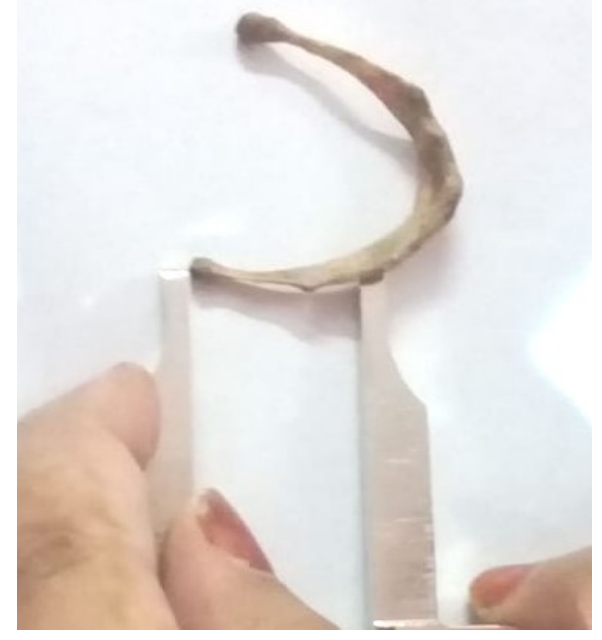

Fig. 2: Showing the distance between the right and left greater horns.

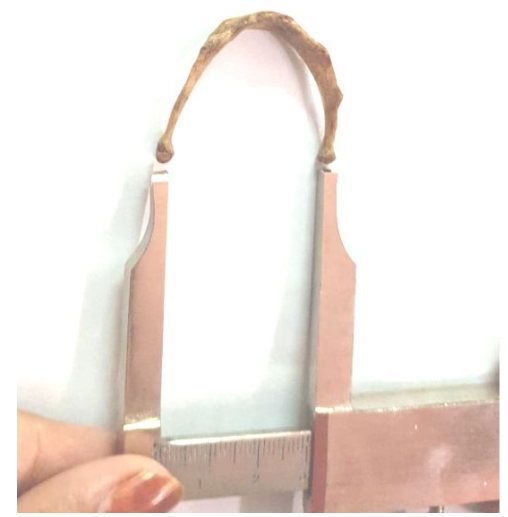

Fig. 3: Showing the width (Side to side dimension)of the body of the hyoid bone.

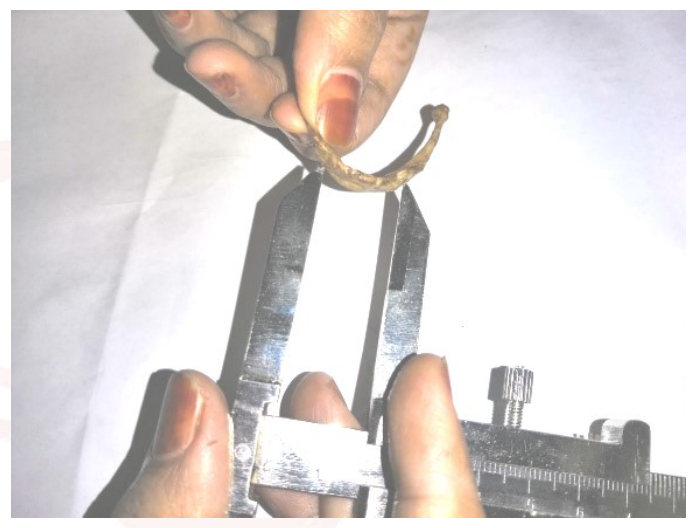

Fig. 4: Showing the height(From the upper border to lower border of body at its center) of the body of the hyoid bone.

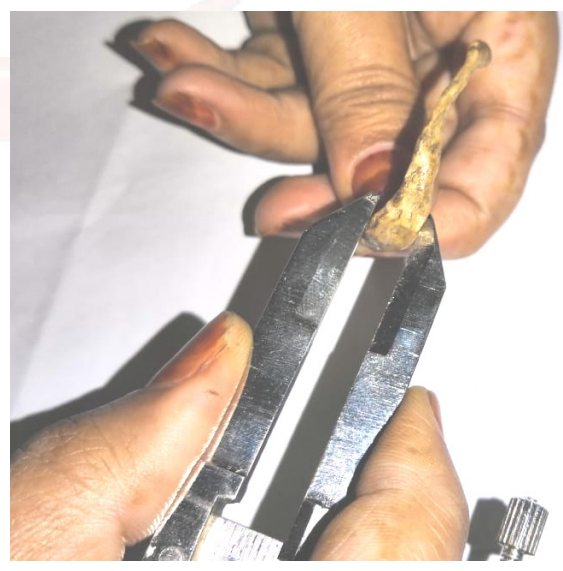

Fig 5: Showing the (Antero-posterior dimension) thickness of the body of the hyoid bone

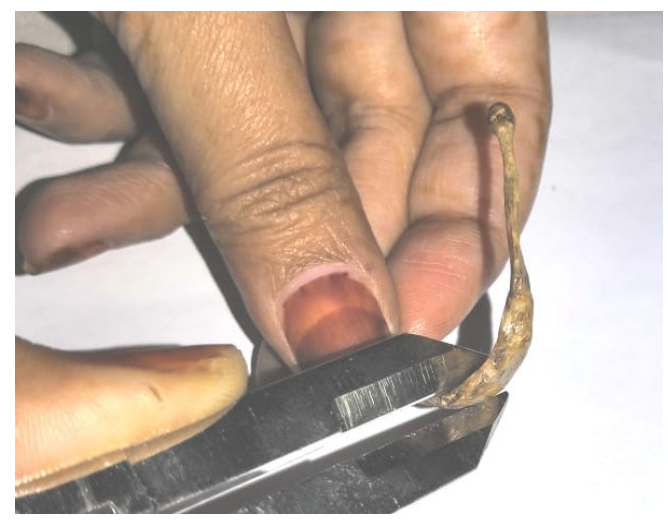




\section{RESULTS}

Table 1: Showing the Mean, standard deviations and the level of significance of all the parameters measured.

\begin{tabular}{|l|c|c|c|c|}
\hline \multicolumn{1}{|c|}{ Parameter } & Male $(\mathrm{n}=\mathbf{3 0})$ & Female $(\mathrm{n}=30)$ & \multicolumn{2}{c|}{ Level of significance } \\
\cline { 5 - 6 } & in $\mathrm{mm}$ & $\mathrm{inm}$ & t value & P value \\
\hline Length of right greater horn & $31.93 \pm 3.04$ & $28.51 \pm 2.69$ & 4.6 & 0.000012 \\
\hline Length of left greater horn & $31.13 \pm 4.19$ & $28.38 \pm 2.49$ & 3.08 & 0.0015 \\
\hline Total hyoid length & $35.85 \pm 2.93$ & $31.95 \pm 2.88$ & 5.184 & 0.00001 \\
\hline $\begin{array}{l}\text { Transverse distance between the distal } \\
\text { ends of greater horns }\end{array}$ & $43.55 \pm 6.77$ & $35.03 \pm 6.16$ & 3.36 & 0.0006 \\
\hline Anteroposterior dimension of the body & $6.16 \pm 1.19$ & $5.55 \pm 1.03$ & 2.13 & 0.018 \\
\hline Height of the body of hyoid bone & $11.17 \pm 1.47$ & $10.03 \pm 1.02$ & 5.14 & 0.00001 \\
\hline Width of the body & $23.08 \pm 2.66$ & $20.12 \pm 1.51$ & 5.19 & 0.00001 \\
\hline
\end{tabular}

Fig. 6: Bar diagram showing the difference between the male and female groups of all the parameters.

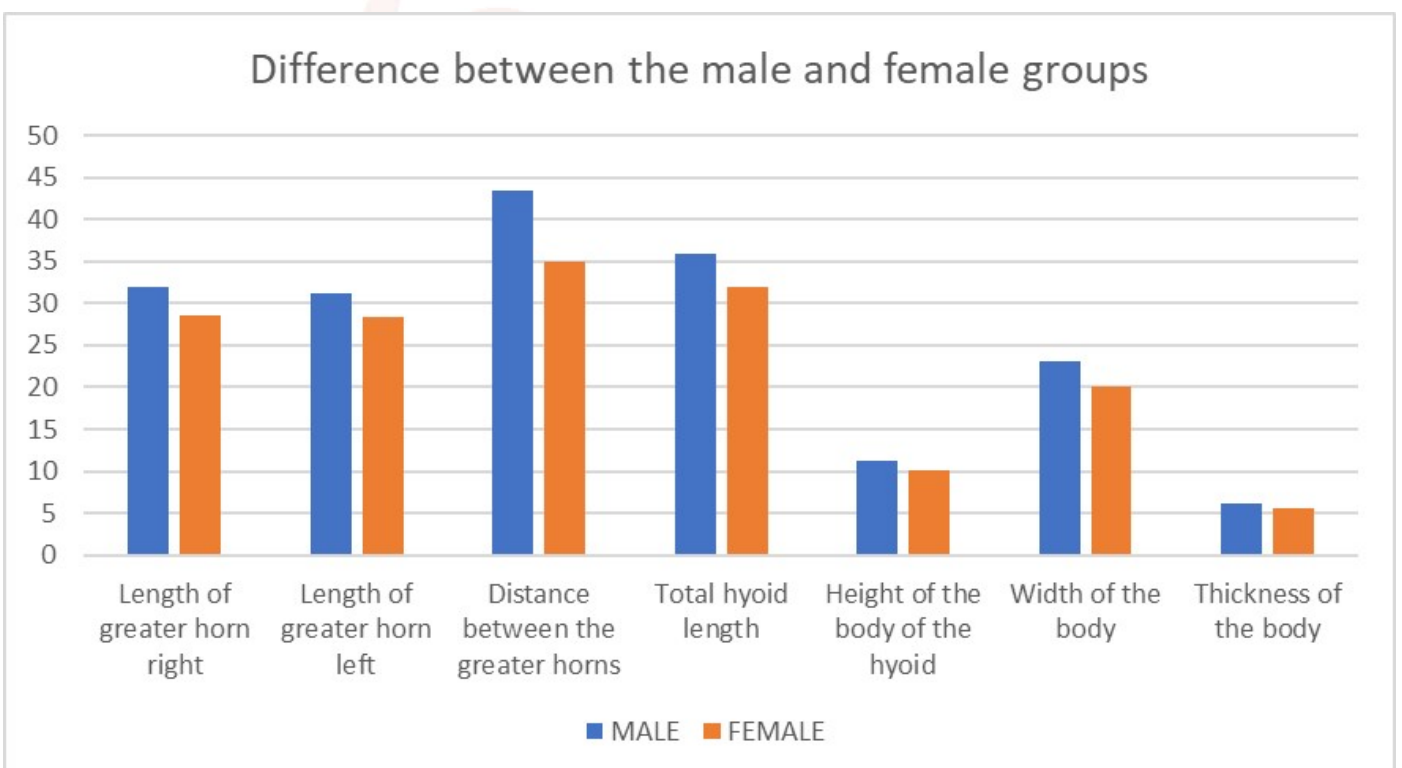

The mean and standard deviation of all parameters were calculated and tabulated in Table 1. All parameters were showing statistically significant difference between the male and female hyoid bones. The level of significance was considered as $P<0.05$. All parameters measured were found to be greater in males than in females (Table 1\& Figure 6).Sexual dimorphism was observed in all the parameters as there was a difference between the mean of all parameters measured in male and female groups and were either highly significant $(P<0.001)$ or significant $(P 0.001$ and $P<0.05)$.

\section{DISCUSSION}

Identification of the human body is often a difficult task in many criminal cases where the dead body is decomposed by the time it has been noticed. The loss of soft tissues in a putrefied body makes facial recognition difficult, hence sex determination will have to be done with skeletal remains which may help in the identification of an individual [5]. In the present study morphometric parameters were measured in the hyoid bones of male and females groups and a statistically significant difference was found between male and female groups.

The average distance between the distal ends of the greater horns of the hyoid bone in males was $43.55 \mathrm{~mm}$ and in females was $35.03 \mathrm{~mm}$, which was close to the other Indian studies by Thippesh Kumar $\mathrm{N}$ et al., Deepak Herald D"Souza et al., and Mukhopadhyay PP et al., where they had found it to be $44.45 \mathrm{~mm}$ in males and 37.89 $\mathrm{mm}$ in females, $42.86 \mathrm{~mm}$ in males and $35.58 \mathrm{~mm}$ in females, and $43.7 \mathrm{~mm}$ in males and $38.4 \mathrm{~mm}$ in females respectively [5-7]. An Anatolian study suggests ethnic variation in the hyoid bone morphometry [8].

In the present study the average length of the greater horn of hyoid bone in male groups was 
observed to be $31.93 \pm 3.04 \mathrm{~mm}$ and $31.13 \pm$ $4.19 \mathrm{~mm}$ on the right and left sides respectively, which was higher than the female group where it was observed to be $28.51 \pm 2.69 \mathrm{~mm}$ and 28.38 $\pm 2.49 \mathrm{~mm}$ on the right and left sides respectively. The present study values were correlating with the results of Durga Venkata Santhi Priya Kothapalli et al., where they found the length of greater horn of hyoid in males to be $32.58 \pm 2.34 \mathrm{~mm}$ and in females $28.43 \pm 2.34$ $\mathrm{mm}$ on its right side and on the left side in males $32.37 \pm 2.13 \mathrm{~mm}$ and in females is $28.42 \pm 2.32$ $\mathrm{mm}$. These were much higher when compared to a Croatian study by Igor Leksan et al., where they have found it to be $29.4 \mathrm{~mm}$ in males on the right side and $29.3 \mathrm{~mm}$ on the left side, and in females, $23.6 \mathrm{~mm}$ on right side and $23.7 \mathrm{~mm}$ on left side, which shows ethnic variation $[9,10]$.

The total height of the hyoid bone in the present study was $35.85 \mathrm{~mm}$ in males and $31.95 \mathrm{~mm}$ in females, where as another Indian study by Thippesh kumar $\mathrm{N}$ reported the total height of the hyoid bone as $39.68 \mathrm{~mm}$ in males and 32.27 $\mathrm{mm}$ in females which was higher than the present study [6]. Mukhopadhyaya PP reported as $37.42 \mathrm{~mm}$ in males and $31.92 \mathrm{~mm}$ in females which was nearer to the present study [7].

The height of the body of hyoid bone in the present study was $11.17 \mathrm{~mm}$ in males and 10.03 $\mathrm{mm}$ in females which was very close to the observations by Durga Venkata Shanthi Priya et al.,Thippesh Kumar N et al., Mukhopadhyay PP where it was $11.85 \mathrm{~mm}$ in males and $10.04 \mathrm{~mm}$ in females, $11.46 \mathrm{~mm}$ in males and $10.96 \mathrm{~mm}$ in females, $11.34 \mathrm{~mm}$ in males and $9.75 \mathrm{~mm}$ in females respectively $[6,7,9]$. The width or side to side dimension of the body was $23.08 \mathrm{~mm}$ in males and $20.12 \mathrm{~mm}$ in females whereas Poonam Vohar et al., reported it as $25.94 \mathrm{~mm}$ in males and $25.05 \mathrm{~mm}$ in females which was little higher than the present study. The anteroposterior dimension or thickness of the body of hyoid bone was $6.16 \mathrm{~mm}$ in males and $5.55 \mathrm{~mm}$ in females whereas Poonam Vohar et al., reported it as $3.67 \mathrm{~mm}$ in males and $3.4 \mathrm{~mm}$ in females [11]. Hence, thickness of the hyoid was found to be much greater in the present study.

The present study was carried out on hyoid bones belonging to Telangana Region. All the parameters were similar with the studies of other
Indian population. Hence regional variation was not observed.

\section{CONCLUSION}

All the parameters considered in the present study were showing significant sexual dimorphism as male hyoid bones were much larger in size when compared to female hyoid bones. These parameters can be considered in forensic investigations for the sex determination of an individual.

\section{Conflicts of Interests: None}

\section{REFERENCES}

[1]. Susan Standring et al. Gray's Anatomy-The Anatomical Basis of Clinical Practice, 40th edition, 2008, P: 436.

[2]. Tsai HH. The positional changes of hyoid bone in children. J ClinPediatr Dent 2002; 27:29-34.

[3]. OP Murthy, KSNarayana Reddy. The Essentials of Forensic Medicine and Toxicology: 33rd Edition: Jaypee Brothers Medical Publishers; 2015.

[4]. Mukhopadhyay PP. Determination of sex from an autopsy sample of adult hyoid bones. Medicine, Science and the Law. 2012; 52: 152-5.

[5]. D'Souza DH, Kiran J and Harish SS. Determination of sex by shape and size of hyoid bone. Journal of Indian Academy of Forensic Medicine. 2013; 35: 145-7.

[6]. Thippesh Kumar N, AbhijitRudra. Estimation of Various Measurements of Hyoid Bone and its Co-Relation with sex of the Individual- An Autopsy Study. JMSCR. 2018; 6 (4): 644-652.

[7]. Mukhopadhyay PP. Morphometric features and sexual dimorphism of adult hyoid bone: a population specific study with forensic implications. Journal of forensic and legal medicine. 2010; 17: 321-4.

[8]. CemKopuzGürselOrtug. Variable Morphology of the Hyoid Bone in Anatolian Population: Clinical Implications - A Cadaveric Study. Int. J. Morphol., 2016; 34(4):1396-1403.

[9]. DurgaVenkataSanthiPriyaKothapalli, PavanaKumari K V, G. ArunaKumari. Sexual dimorphism of hyoid bone. Journal of Bioscience and Technology. 6(2): 2015: 653-657.

[10]. Leksan, I.; Marcikic, M.; Nikolic, V.; Radic, R.; Selthofer, R. Morphological classification and sexual dimorphism of hyoid bone: New approach. Cell. Anthropol. 2005; 29(1):237-42.

[11]. PoonamVohar, Pratima Kulkarni. Sexual dimorphism of human hyoid bone. International Journal of Anatomy and Research. 2017; 5(1):3607-10.

How to cite this article: Syeda Sadia Sameera, K Ephraim Vikram Rao. MORPHOMETRIC ANALYSIS AND SEXUAL DIMORPHISM OF HYOID BONE IN TELANGANA POPULATION. Int J Anat Res 2019;7(4.1):7038-7041. DOI: 10.16965/ijar.2019.298 